\title{
SCIDOC
}

\author{
International Journal of Dentistry and Oral Science (IJDOS) \\ ISSN: 2377-8075
}

\section{Hydration Matters, Role Of Body Hydration In Pain Control During Endodontic Therapy}

Research Article

Usman Sana $^{1 *}$, Attiqueur Rehman ${ }^{2}$, Sobia Masood Tirmazi ${ }^{3}$, SaqibNaeem Siddique ${ }^{4}$, Mehwish Munawar ${ }^{5}$, Nasrullah khan ${ }^{6}$

${ }^{1}$ Assistant Professor and Head Department of Operative Dentistry, Islam Dental College, Sialkot, Pakistan.

${ }^{2}$ Assistant Professor, Department of Operative Dentistry, Azra Naheed Dental College, Lahore, Pakistan.

${ }^{3}$ Assistant Professor, Department of Operative Dentistry, Institute of dentistry; CMH Lahore medical college, Lahore, Pakistan.

${ }^{4}$ Assistant Professor, Department of Operative Dentistry, University College of Dentistry, University of Lahore, Pakistan.

${ }^{5}$ Assistant Professor, Department of Operative Dentistry, Azra Naheed Dental College, Lahore, Pakistan.

${ }^{6}$ Assistant Professor, Oral Medicine Avicenna Dental College, Lahore, Pakistan.

\section{Abstract}

Objective: To assess the relationship of body hydration levels and its impact on pain control during endodontic therapy. Methods: 500 patients were included who required endodontic therapy for irreversible pulpitis. Patient's body weight was measured in kilograms, while their hydration was calculated the number of glasses of water consumed daily. The pain was measured using the numeric pain for the level of pain perceived during endodontic treatment. Data collection and analysis was done using SPSS version 23.

Results: A significant correlations exist between patient's pain perception during endodontic therapy and their body hydration levels. Our findings suggest that pain levels during endodontic procedures can be reduced with adequate body hydration. Conclusion: Pre-operative assessment of patient's hydration can help reduce pain during endodontic treatment. Hence, it is important to consider adequately water intake to reduce pain during the endodontic treatment.

Keywords: Water Intake; Body Hydration; Endodontic Treatment; Pain.

\section{Introduction}

Endodontic therapy is a painful and a multifactorial procedure. Local anesthetics are used to reduce pain during endodontic treatment [1]. Many patients perceive local anaesthetic injection as the main pain causative procedure during treatment [2]. Multiple factors can affect the pain perception, reason being that pain is a multifactorial phenomenon.Variables like proprioception1, pressure [3] and patient attributes [4] are factors that impact pain perception during endodontic treatment. The effects of temperature have also been observed in the efficacy of local anaestheticds3. Physiological aspects like body hydration and body weight have an important role in management of pain during endodontic therapy [5]. Hemodynamic and the body ability to adapt to the rapid change in autonomic systemis dependent upon blood volume and the sympathetic and parasympathetic drive [10]. Other important factors in this context are the blood volume and body hydration levels [11]. Predominantly patients are apprehensive when it comes to endodontic treatment [6]. This anxiety interferes with patient's compliance affecting their overall health.[7]. Perception of pain is a multi-factorial, physical and emotional phenomenon [8]. And we know that human emotional state is also responsible for modulation of pain [9].

Research has proven that anxiety and pain are inter-related, complex processes. [9-15]. The aim of the study was to identify the relationship of body hydration and its impact on pain during endodontic therapy.

\section{Patients and Methods}

Study was conducted in the department of Operative dentistry,

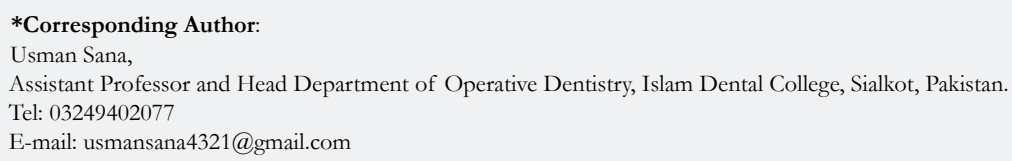

Copyright: Usman Sana ${ }^{\circ} 2021$. This is an open-access article distributed under the terms of the Creative Commons Attribution License, which permits unrestricted use, distribution and reproduction in any medium, provided the original author and source are credited. 
Islam Dental College, Sialkot. The period of study was from August to December 2020. Approval from ethical committee was secured. Age range of the patients was from 12-70 years. Patient's presenting with irreversible pulpitis were included in the study. Exclusion criteria was; patients on systemic disease medications, drug abuse and mental disorders.

Patient's body weight was documented kilograms. While the body hydration levels were recorded by the number of glasses of water that the patients consumed in one day. Inferior alveolar nerve block was administered and access opening performed, the numeric pain scale questionnaire was used to document subjective response to pain during endodontic treatment. On the 1-10 numeric pain scale, 1-2 represented mild pain, 2-5 represented moderate pain, 6-7 represented severe pain while 8-10 represented extreme pain [9]. Data collection and analysis were performed using SPSS version 23.

\section{Results}

A total of 500 patients were included (206 females, 294 males). Tables 1 represents the frequency of gender. Table 2 represents the frequency of pain. Figure 1 represents the frequency distribution of age. Table 3 represents the number of glasses of water that the subjects were consuming. Table 4 represents cross tabulation between pain and body hydration. Table 5 represents the correlation between body hydration and pain.

Table 1. Gender.

\begin{tabular}{|c|c|c|c|c|c|}
\hline \multicolumn{2}{|c|}{} & Frequency & Percent & Valid Percent & Cumulative Percent \\
\hline \multirow{4}{*}{ Valid } & $\mathrm{M}$ & 206 & 41.2 & 41.2 & 41.2 \\
\cline { 2 - 6 } & $\mathrm{F}$ & 294 & 58.8 & 58.8 & \\
\cline { 2 - 6 } & Total & 500 & 100.0 & 100.0 & 100.0 \\
\hline
\end{tabular}

Table 2. Pain.

\begin{tabular}{|c|c|c|c|c|}
\hline \multicolumn{5}{|c|}{ Numeric Pain Scale } \\
\hline & Frequency & Percent & Valid Percent & Cumulative Percent \\
\hline mild pain (1-3) & 250 & 50 & 50 & 50 \\
\hline moderate pain (4-6) & 158 & 31.6 & 31.6 & 81.6 \\
\hline severe pain (7-10) & 92 & 18.4 & 18.4 & \\
\hline Total & 500 & 100.0 & 100.0 & 100.0 \\
\hline
\end{tabular}

Table 3. Body Hydration.

\begin{tabular}{|c|c|c|c|c|c|}
\hline \multicolumn{6}{|c|}{ Hydration } \\
\hline \multirow{3}{*}{ Valid } & Frequency & Percent & Valid Percent & Cumulative Percent \\
\cline { 2 - 6 } & under-hydrated (<8 glasses) & 164 & 32.8 & 32.8 & 32.8 \\
\cline { 2 - 6 } & adequate hydrated (>8 glasses) & 336 & 67.2 & 67.2 & \\
\cline { 2 - 6 } & Total & 500 & 100 & 100 & 100 \\
\hline
\end{tabular}

Table 4. Cross-tabulation between pain and hydration.

\begin{tabular}{|c|c|c|c|c|c|}
\hline \multicolumn{6}{|c|}{ Hydration and Numeric Pain Scale } \\
\hline \multirow{2}{*}{} & \multicolumn{3}{c|}{ Numeric Pain Scale } & \multirow{2}{*}{ Total } \\
\cline { 3 - 6 } \multicolumn{2}{|c|}{} & mild pain (1-3) & moderate pain (4-6) & severe pain (7-10) & \\
\hline \multirow{2}{*}{ Hydration } & under-hydrated (<8 glasses) & 64 & 58 & 42 & 164 \\
\cline { 2 - 6 } & adequate hydrated (>8 glasses) & 186 & 100 & 50 & 336 \\
\hline \multicolumn{2}{|c|}{ Total } & 250 & 158 & 92 & 500 \\
\hline
\end{tabular}

Table 5. Correlation between Hydration and Pain.

\begin{tabular}{|c|c|c|c|c|}
\hline \multicolumn{5}{|c|}{ Correlations } \\
\hline & & Hydration & Weight & Numeric PainScale \\
\hline \multirow{3}{*}{ Hydration } & Pearson Correlation & 1 & 0.015 & $-.166 * *$ \\
\hline & Sig. (2-tailed) & & 0.73 & 0 \\
\hline & $\mathrm{N}$ & 500 & 500 & 500 \\
\hline \multirow{3}{*}{$\begin{array}{l}\text { Numeric } \\
\text { Pain Scale }\end{array}$} & Pearson Correlation & $-.166^{* *}$ & 0.013 & 1 \\
\hline & Sig. (2-tailed) & 0 & 0.776 & \\
\hline & $\mathrm{N}$ & 500 & 500 & 500 \\
\hline
\end{tabular}


Figure 1. Frequency of Age.

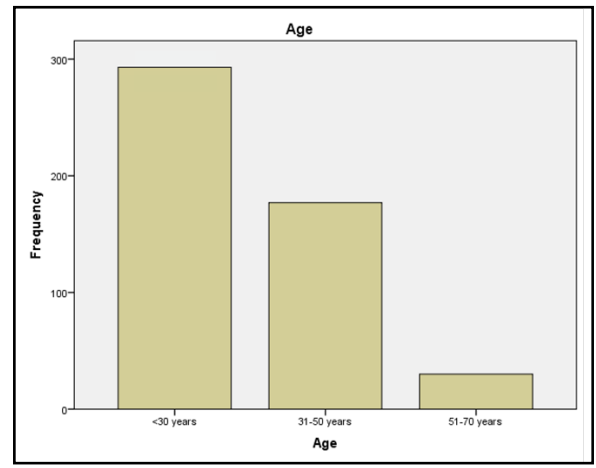

Out of 164 cases who were under hydrated reported with mild pain in 64 cases, moderate pain in 58 cases and severe pain in 42 cases. While out of 336 adequately hydrated cases 186 presented with mild pain, 100 with moderate pain and 50 with severe pain.

The significance between pain and hydration is -.166. There exits strong correlation between body hydration and endodontic pain.

\section{Discussion}

Anxiety and fear of dental procedures is one of the major factors in preventing patient from seeking dental care [12]. Patient's pain perception and its interpretation is a multifactorial phenomenon that is influenced by multiple factors [18]. When it comes to the fundamental factors, one of which is body hydration, blood hemodynamic, sympathetic and para-sympathetic system must be considered [10]. Adequate body hydration is one of the fundamentals that must be considered, reason being that our hemodynamic system efficiency is interlinked to the body hydration levels [11]. The hemodynamic system works efficiently only when the body is adequately hydrated. Body hydration level is going to support the circulatory system and the sympathetic drive to overcome anxiety and related pain during dental procedures [13].

Other variables also play a significant role in pain control like distensibility [1], speed of injection [3] and patient characteristics [4]. Physiological aspects like body hydration and body weight have an important role in management of anxiety and pain associated with local anaesthesia [14]. Body's ability to adapt to the rapid change in autonomic drive is dependent upon blood volume and the sympathetic and parasympathetic drive [10]. Another important factor in this context is the blood volume and body hydration levels.

Relation between body hydration and its association with pain has been proven [11-13]. Our finding suggests that there is a strong correlation between adequate body hydration levels and pain control during endodontic treatment. Although many other factors do play role in determining pain during endodontic therapy. Apart from role in effective regulation of the sympathetic system, adequate body hydration plays significant role in body digestion, improving state of well-being due to serotonin release by the gut, improving patient sleep, regulation of neurotransmitters, and control of hormonal balance in the body [16]. Brain functioning and related thinking processes are strongly related to body hydration levels [17]. Therefore, adequate body hydration not only helps directly in pain and anxiety management of dental patients, but also is indirectly responsible for achieving body homeostasis at a larger scale [18].

Therefore, in an attempt to improve the level of endodontic care with minimal patient discomfort and improve the quality of dental services we must consider adequate body hydration. This is very much possible by modifying life style of the patients presenting with dental issues. Simple life style modifications [19] like increasing the number of glasses of water intake to improve general and associated dental health seems a sensible strategy to improve dental care by reducing cost. Incorporating a fundamental factor like water intake [21], a mechanism to follow up and educate your dental patients is a cost-effective solution when compared with sedation and general anaesthesia options for overcoming fears associated with nerve block related anxiety and pain. Adequate hydration also improves the saliva flow rate, putting the patient from a high caries risk to moderate or even low caries risk rate [23].

Hydration and pain have a significant correlation, and the level of correlation between the two factors is -.166. If the patient is dehydrated, the pain levels will increase and complicate treatment both for the dentist and the patient.

Dental professionals should consider educating the patient about the relationship of adequate body hydration and its role is over all patients' health and wellbeing [24, 25]. Therefore assessing the patient's hydration levels, in number of glasses consumed per day and taking adequate measures to improve endodontic treatment outcome will cast a positive impact.Significant clinical benefit can be achieved by simple life style modifications [20, 22].

\section{Conclusion}

Pre-operative assessment and educating the dental patient helps reduce situations of painful experiences. Educating our patients regarding body hydration, its impact on general and dental health will have positive impact on their lives. On top pain control can be improved by life style modification as simple as adequate body hydration. Adequate body hydration will not only help patients improve their dental treatment compliance but it is also going to impact their overall general health.

\section{References}

[1]. Nagendrababu V, Pulikkotil SJ, Suresh A, Veettil SK, Bhatia S, Setzer FC. Efficacy of local anaesthetic solutions on the success of inferior alveolar nerve block in patients with irreversible pulpitis: a systematic review and network meta-analysis of randomized clinical trials. IntEndod J. 2019 Jun;52(6):779789. PubMed PMID: 30638269.

[2]. Ahmad AH, Zakaria R. Pain in Times of Stress. Malays J Med Sci. 2015 
Dec;22(Spec Issue):52-61. PubMed PMID: 27006638.

[3]. Lauriola M, Tomai M, Palma R, La Spina G, Foglia A, Panetta C, Raniolo M, Pontone S. Intolerance of Uncertainty and Anxiety-Related Dispositions Predict Pain During Upper Endoscopy. Front Psychol. 2019 May 15;10:1112. PubMed PMID: 31156518.

[4]. Angelo Z, Polyvios C. Alternative practices of achieving anaesthesia for dental procedures: a review. J Dent Anesth Pain Med. 2018 Apr;18(2):79-88. PubMed PMID: 29744382.

[5]. Matić IP, Stojadinović T, Matić I, Maslovara S, Veselski K. Change in body weight, body fat and body water in children after tonsilloadenoidectomy. Int J Pediatr Otorhinolaryngol. 2020 Dec;139:110468. PubMed PMID: 33147560.

[6]. Guzeldemir E, Toygar HU, Cilasun U. Pain perception and anxiety during scaling in periodontally healthy subjects. J Periodontol. 2008 Dec;79(12):2247-55. PubMed PMID: 19053913.

[7]. Tickle M, Milsom K, Crawford FI, Aggarwal VR. Predictors of pain associated with routine procedures performed in general dental practice. Community Dent Oral Epidemiol. 2012 Aug;40(4):343-50. PubMed PMID: 22316006.

[8]. Maggirias J, Locker D. Psychological factors and perceptions of pain associated with dental treatment. Community Dent Oral Epidemiol. 2002 Apr;30(2):151-9. PubMed PMID: 12000356.

[9]. Koechlin H, Coakley R, Schechter N, Werner C, Kossowsky J. The role of emotion regulation in chronic pain: A systematic literature review. J Psychosom Res. 2018 Apr;107:38-45. PubMed PMID: 29502762.

[10]. Young HA, Cousins A, Johnston S, Fletcher JM, Benton D. Autonomic adaptations mediate the effect of hydration on brain functioning and mood: Evidence from two randomized controlled trials. Sci Rep. 2019 Nov 11;9(1):16412. PubMed PMID: 31712590.

[11]. Sharma R, Sharma S. Physiology, Blood Volume. 2021 Apr 20. In: StatPearls [Internet]. Treasure Island (FL): StatPearls Publishing; 2021 Jan-. PubMed PMID: 30252333.

[12]. Lin CS, Wu SY, Yi CA. Association between Anxiety and Pain in Dental Treatment: A Systematic Review and Meta-analysis. J Dent Res. 2017 Feb;96(2):153-162. PubMed PMID: 28106507.

[13]. Smith JA, Pati D, Wang L, de Kloet AD, Frazier CJ, Krause EG. Hydration and beyond: neuropeptides as mediators of hydromineral balance, anxiety and stress-responsiveness. Front SystNeurosci. 2015 Mar 31;9:46. PubMed PMID: 25873866.

[14]. Hashimoto S, Yamashiro M, Fujita K, Yasuda A, Sunada K. Effects of epinephrine on lidocaine pharmacokinetics and blood volume in the dental pulp. J Endod. 2014 Sep;40(9):1370-4. PubMed PMID: 25146017.

[15]. Loggia ML, Schweinhardt P, Villemure C, Bushnell MC. Effects of psychological state on pain perception in the dental environment. J Can Dent Assoc. 2008 Sep;74(7):651-6. PubMed PMID: 18789200.

[16]. Armstrong LE, Johnson EC. Water Intake, Water Balance, and the Elusive Daily Water Requirement. Nutrients. 2018 Dec 5;10(12):1928. PubMed PMID: 30563134.

[17]. Pross N. Effects of Dehydration on Brain Functioning: A Life-Span Perspective. Ann NutrMetab. 2017;70Suppl 1:30-36. PubMed PMID: 28614811.

[18]. Da Costa RS, Ribeiro SN, Cabral ED. Determinants of painful experienceduring dental treatment. Rev Dor São Paulo 2012;13:365-70.

[19]. Deng G. Integrative Medicine Therapies for Pain Management in Cancer Patients. Cancer J. 2019 Sep/Oct;25(5):343-348. PubMed PMID: 31567462.

[20]. Milgrom P, Weinstein P, Golletz D, Leroux B, Domoto P. Pain management in school-aged children by private and public clinic practice dentists. Pediatr Dent. 1994 Jul-Aug;16(4):294-300. PubMed PMID: 7937263.

[21]. Moyen NE, Ganio MS, Wiersma LD, Kavouras SA, Gray M, McDermott BP, Adams JD, Binns AP, Judelson DA, McKenzie AL, Johnson EC, Muñoz CX, Kunces LJ, Armstrong LE. Hydration status affects mood state and pain sensation during ultra-endurance cycling. J Sports Sci. 2015;33(18):1962-9. PubMed PMID: 25793570.

[22]. Morse Z, Sano K, Fujii K, Kanri T. Sedation in Japanese dental schools. AnesthProg. 2004;51(3):95-101. PubMed PMID: 15497299.

[23]. Mobley CC. Nutrition and dental caries. Dent Clin North Am. 2003 Apr;47(2):319-36

[24]. Ma GS. [Hydration status and health]. Zhonghua Yu Fang Yi XueZaZhi. 2019 Apr 6;53(4):337-341. Chinese. PubMed PMID: 30982263.

[25]. El-SharkawyAM, Sahota O, Lobo DN. Acute and chronic effects of hydration status on health. Nutr Rev. 2015 Sep;73Suppl 2:97-109. PubMed PMID: 26290295. 